\title{
Tokyo's plan for new campus under threat
}

[TОКYO] An ambitious plan by Tokyo University to build an 89-acre campus, 20 miles from the city centre, is hanging in the balance.

The university has run into difficulties in raising funds to buy the land in Kashiwa, Chiba prefecture. Other problems include a lack of enthusiasm among the university's existing departments for the creation of a new 'centre of excellence' at Kashiwa, and concern about the upper age limit of 35 for recruits to 14 planned new research groups.

These groups form part of the university's '21st Century Project', intended to exploit promising new areas of science. Research groups in areas such as materials science, energy, communications, life sciences and environmental science are planned to be set up by April next year.

But this will happen only if the financial prospects improve. In 1995, the university bought 29 acres of the land using funds allocated by the Ministry of Education, Science, Sports and Culture (Monbusho) as part of the supplementary budget. The university intended to sell a site belonging to the Institute of Solid State Physics (ISSP) in Roppongi, central Tokyo, and use the proceeds to buy the remaining 60 acres of land in Kashiwa.

But a recent collapse in Tokyo land prices has reduced the value of the Roppongi campus too far to cover the price of the Kashiwa campus. The university recently failed to persuade Monbusho to purchase the land.

According to Tokyo University, the new research groups, which will start operating next year, will initially be based at the main campus in Hongo, central Tokyo, but will transfer to Kashiwa later. Some researchers now feel that this is unlikely to happen.

"We have the feeling that the new research groups will stay permanently at the main campus in Hongo," says one researcher in the department of physics.

Others are more optimistic. Shuntaro Watanabe, a professor in advanced spectroscopy at ISSP, suggests that, rather than the Roppongi campus, the university might sell the site of the Institute of Cosmic Ray Research in Tanashi, on Tokyo's outskirts. He also predicts that the university is likely to be granted extra funds from the government's $¥ 16,000$ billion (US\$124 billion) economic stimulus package, unveiled last week to help boost the sluggish economy.

The scheme to create a new centre of excellence for postgraduate research in the suburbs was launched by Hiroyuki Yoshikawa, the former president of Tokyo University. But individual departments have since begun trying to build their own centres of excellence at the existing campuses.

Meanwhile there is concern that the new campus is eating up money that would otherwise be spent on repairing old, dilapidated departmental buildings. Funds are also needed to complete a building for the faculty of science on the main campus (see Nature 355, 99; 1992): five years behind schedule, it already houses several departments.

There have also been criticisms of the university's management over recruitment for the impending research programme. Many scientists were disappointed to find out that advertisements carried strict age restrictions - new assistant professors, for example, could be no older than 35 .

Some researchers feel this restriction, intended to bring new blood into the university, is too strict. One professor at the university's Research Centre for Advanced Science and Technology (RCAST), argues that it violates scientists' right to equal opportunities. He says it virtually rules out everyone who has carried out research abroad or in industry, or obtained an MD.

"Although the university is outwardly promoting a policy to appoint 'bright young things', it is evident that they are creating a bureaucratic fast-track system for young, but not necessarily talented, researchers within the university," he says.

Some researchers even fear that the new assistant professors have already been selected by staff who lead powerful factions within the university. They are concerned that this practice, apparently not unusual in the university, contradicts its aim of producing internationally competitive researchers.

Protests by angry scientists are said to have forced the university committee to remove the age restriction, while RCAST, a comparatively forward-thinking institute within Tokyo University, is considering introducing an equal opportunity policy in the near future.

AsakoSaegusa

\section{Russian students warn of demonstrations over spending cuts}

[MOscow] Students have launched a nationwide protest against proposals for university reform by Russia's minister of education, Alexander Tikhonov. They say the reforms could lead to a steep fall in the number of graduates and a significant increase in students' costs.

The Russian Association of University Students Trade Unions has sent an official note of protest to Tikhonov, President Boris Yeltsin and Gennagy Seleznev, the speaker of the Duma (the lower chamber of the Russian parliament).

The association has 2.6 million members, 70 per cent of Russia's student population, and plans to hold a nationwide protest that is likely to affect public opinion.

Last year the streets of the major university towns, including Moscow, St Petersburg, Nizhny Novgorod and Tula, saw local demonstrations, but these were little more than the traditional protests against the usual difficulties faced by students.

This time, the students argue that the reforms threaten to undermine the whole

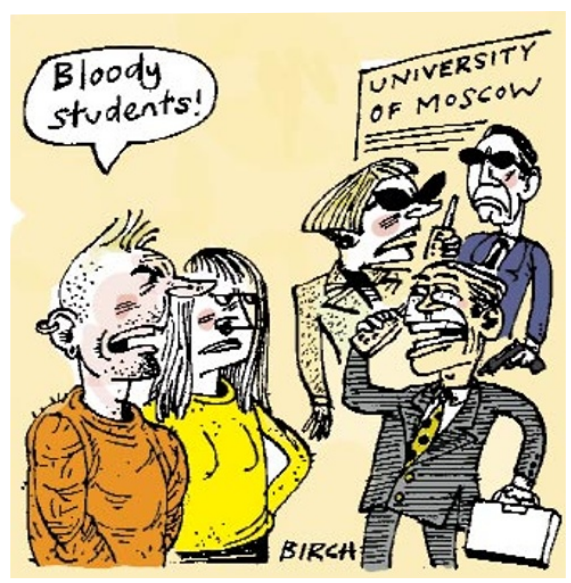

higher education system. Their action could paralyse cities and block federal highways.

"We will try to avoid extremism, but cannot guarantee order," said Mikhail Mirsky, deputy chairman of the student association. "Tikhonov has created a scheme that could lead to the total annihilation of Russian universities. He will only be helping students who belong to rich families. The number of students paid for out of the state budget is to be cut by 10 per cent."

Mirsky points out that these changes are taking place as the price of accommodation is soaring, and students must for the first time pay for textbooks. "We predict that within three to four years the number of students will have fallen by 40 to 50 per cent, at a time when the government increasingly needs graduates," he says.

Tikhonov, son of the former Soviet prime minister Nikolai Tikhonov, has said he intends to solve the growing problems of Russian higher education by "searching for resources outside the state budget".

For example, he is suggesting that universities should be able to lease buildings to private companies. But he also wants a reduction in the number of universities, the length of courses - from six to four years and the ratio of lecturers to students. The student association complains that such moves will inevitably lead to widespread corruption and to campuses being occupied by businessmen.

Carl Levitin 